\title{
Generation and Screening of Transgenic Mice with Neuronal Labeling Controlled by Thy1 Regulatory Elements
}

\author{
Petar Marinković, Leanne Godinho, and Thomas Misgeld
}

\begin{abstract}
Major progress has been made using in vivo imaging in mice to study mammalian nervous system development, plasticity, and disease. This progress has depended in part on the wide availability of twophoton microscopy, which is capable of penetrating deep into scattering tissue. Equally important, however, is the generation of suitable transgenic mouse models, which provide a "Golgi staining"-like labeling of neurons that is sparse and bright enough for in vivo imaging. Particularly prominent among such transgenic mice are the so-called Thyl-XFP mice (in which XFP stands for any fluorescent protein) that are used in numerous studies, especially to visualize spine plasticity in the cortex and remodeling in peripheral synapses. New generations of Thy1-XFP mice are now being generated at a high rate, and these have allowed previously difficult experiments to become feasible. Moreover, with easy access to core facilities or commercial providers of pronuclear injections, generating simple Thy 1 transgenic mice is now a possibility even for small laboratories. In this introduction, we discuss the Thyl regulatory elements used to generate transgenic lines with neuronal labeling. We provide a brief overview of currently available Thyl transgenic mice, including lines labeling neuronal organelles or reporting neuronal function.
\end{abstract}

Thanks to Golgi's reazione nera, the value of high-contrast labeling of stochastic subsets of nerve cells has been apparent since the dawn of modern neuroscience (Ramon y Cajal 1904). However, translating these early achievements into a method to observe nerve cells in vivo over time has required another century of technological development. With the advent of two-photon microscopy and major advances in fluorescent protein development, such studies have now become feasible. Although many different approaches to such studies have been explored (Young and Feng 2004), most recent chronic in vivo imaging studies of nerve cells in the central nervous system (CNS) and peripheral nervous system (PNS) have taken advantage of transgenic mice that express high levels of fluorescent proteins in subsets of nerve cells driven by murine Thy1 regulatory elements (Lichtman and Sanes 2003; Misgeld and Kerschensteiner 2006; Pan and Gan 2008; Holtmaat and Svoboda 2009; Wilt et al. 2009). A collection of such transgenic mice (Thy1-XFP mice) was first described by Feng et al. (2000), and since then, numerous studies have taken advantage of these original transgenic lines. In addition, many new variants of such mice have been engineered (see Thyl Lines below). The central role that Thyl-XFP mice have come to play in some areas of in vivo imaging and the plethora of lines now available motivate our attempt in this introduction to provide background information about the Thyl promoter itself, the available Thyl lines, and the generation of new ones. Moreover, as core facilities that generate transgenic founder mice for a reasonable fee are now available at most major

Adapted from Imaging in Neuroscience: A Laboratory Manual (ed. Helmchen and Konnerth). CSHL Press, Cold Spring Harbor, NY, USA, 2011.

(C) 2015 Cold Spring Harbor Laboratory Press

Cite this introduction as Cold Spring Harb Protoc; doi:10.1101/pdb.top087668 
P. Marinković et al.

research institutions, generating new Thyl transgenic animals is an option even for relatively small laboratories.

The Thy1 Expression Vector

The Thy 1 expression vector (Fig. 1) is derived from a gene that encodes a small immunoglobin superfamily member, Thy1 (GeneID 21838; Ingraham et al. 1986), which is anchored via glycosylphosphatidylinositol (GPI) to the plasma membrane. Endogenously, murine Thyl is widely expressed on numerous cell types, including immune cells and neurons (Morris 1992). As one of the first discovered surface markers of specific immune cell subsets, effective antibodies became available early. In addition to immunological studies, this allowed detailed exploration of the expression of Thy1 in the nervous system (Morris 1985). Studies of transcriptional regulation followed suit, revealing the strong and broad expression in nerve cells controlled by cis-acting elements within the locus. This allowed tailoring expression toward neuronal specificity, while largely suppressing immune cell expression (Vidal et al. 1990). Together, these features made the Thyl gene the source of wellcharacterized pan-neuronal regulatory elements and an obvious choice for the creation of neuronspecific transgenic mice (Caroni 1997). Originally, Thy1-derived regulatory elements were used to express disease- and remodeling-associated genes (Aigner et al. 1995; Andra et al. 1996). Because the Thyl gene is up-regulated only postnatally in most neuronal populations, the Thyl-driven gene expression in these studies allowed circumventing undesirable developmental effects, without resorting to complex conditional gene-expression strategies. In these studies, the strong variation in

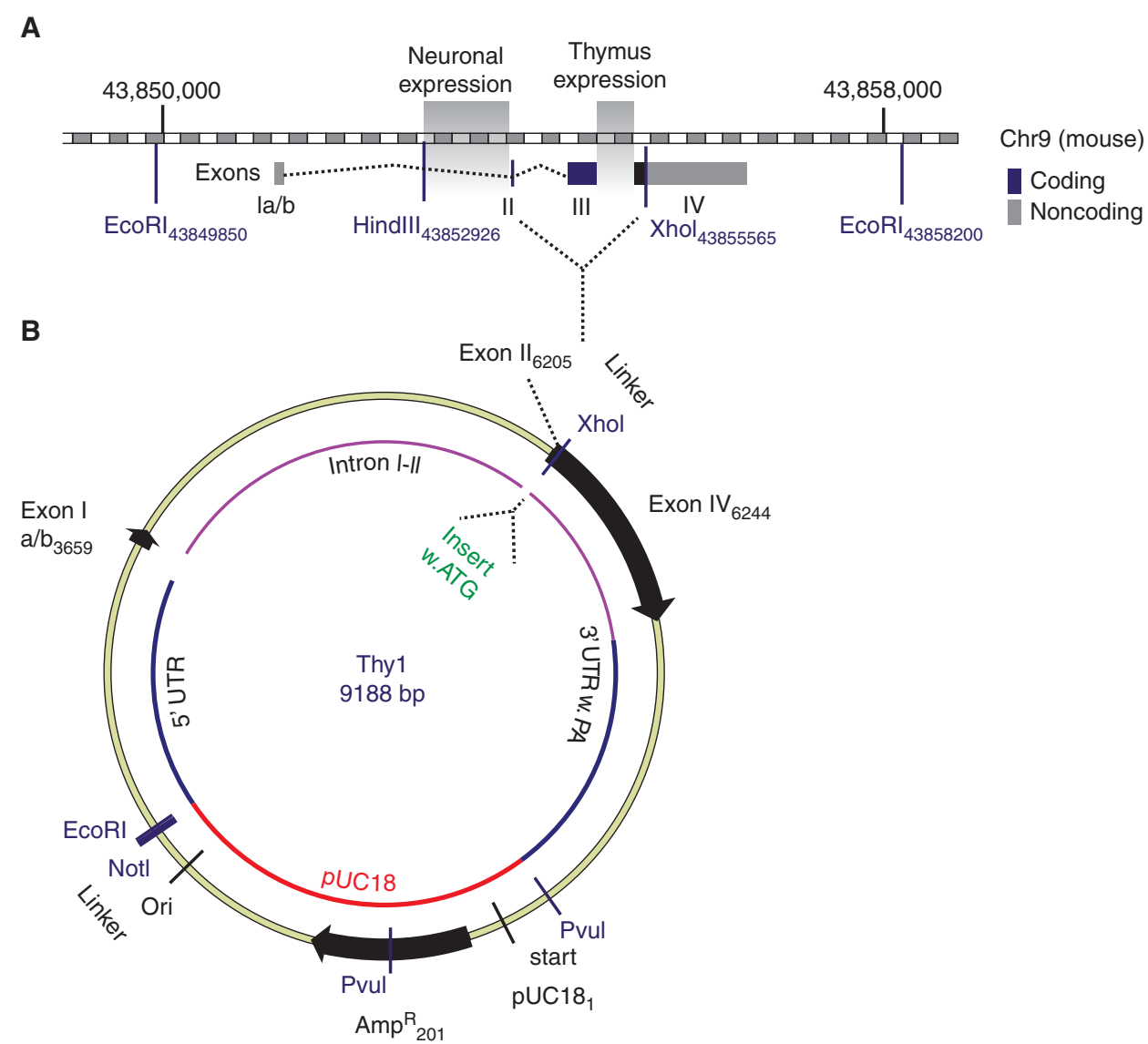

FIGURE 1. The murine Thy 1 locus and the Thy 1 cloning vector. (A) Schematic map of the endogenous Thy 1 locus. (B) Thy 1 cloning vector. The critical restriction sites for cloning are indicated. Important features within the plasmid are annotated. (Modified from Ingraham et al. 1986; Vidal et al. 1990, and Caroni 1997.) 
expression levels among different classes of neurons, but also, more importantly, among individual neurons of the same population, was already noted (Caroni 1997). Although this variation represents a potential problem for studies that use Thy1 regulatory elements to establish pan-neuronal expression of transgenes to test for their biological effects, it has proven an unexpected blessing for studies that aim at revealing neuronal morphology using in vivo imaging.

\section{Stochastic Subset Labeling}

In 2000, Feng and colleagues took advantage of the strong but variable neuronal expression driven by Thy1 regulatory elements to label neurons in vivo (Feng et al. 2000). They described what have become known as Thy1-XFP transgenic mice, a set of 25 transgenic lines with individual expression patterns of green fluorescent protein (GFP), yellow fluorescent protein (YFP), cyan fluorescent protein (CFP), or DsRed. Among these originally described lines were some in which the majority of neurons endogenously expressed the Thyl gene, as well as others that showed a striking Golgi-like labeling pattern (Fig. 2). These Thy1-XFP lines of the first generation are still widely in use, and they can be easily obtained from The Jackson Laboratory (http://www.jax.org). They have been featured in numerous seminal in vivo imaging studies of developmental, physiological, and pathological neuronal plasticity (e.g., Grutzendler et al. 2002; Trachtenberg et al. 2002; Gan et al. 2003; Walsh and Lichtman 2003; Xu et al. 2009; Yang et al. 2009).

One of the most useful features of Thy1-driven expression of fluorescent proteins has proven to be its baffling sensitivity to chromosomal position effects. This results in a wide variety of expression patterns in different founders that originate from pronuclear injection of the same Thy 1 construct (Fig. 3). Expression varies with respect to both the neuronal subpopulations that are labeled and the percentage of cells within a population that expresses the transgene. Although few general rules have held up without exception, certain neuron populations still tend to show expression in most Thy1 transgenic lines. These neuronal populations typically give rise to long-distance projections (e.g., motor neurons, large-diameter dorsal root ganglion neurons, retinal ganglion cells, or cerebellar mossy fibers), but some cells with local projections (e.g., dentate gyrus granule cells in the hippocampus) are also typically labeled. In many lines, subpopulations of excitatory cortical neurons (e.g., pyramidal cells in the cortex or hippocampal region CA1) are labeled to a variable degree. Less commonly, local interneurons, Purkinje cells, climbing fibers, or small-diameter sensory neurons are labeled. However, many unexpected labeling patterns can be found, even in nonneuronal cells. For example, lines have been reported with expression in astrocytes or terminal Schwann cells (Livet et al. 2007). As a general rule, transgene expression becomes detectable during the first postnatal week in most Thy lines in accordance with the developmental profile of endogenous Thy1 expression (Morris 1985). However, Thy1-XFP lines show a wide range of variation with regard to expression onset as well. For example, Thy1-YFP ${ }^{16}$ (Feng et al. 2000) shows strong expression in motor neurons as early as embryonic day 13 (Lichtman and Sanes 2003).

A rather surprising feature of Thyl-driven expression is the fact that within a seemingly homogenous population of neurons (e.g., the motor neurons of a given muscle's motor pool) individual neurons can show strong labeling, while in adjacent cells, such labeling is undetectable. This does not represent a slight difference in the labeling intensity, such that the detection sensitivity creates an arbitrary cutoff above which some brighter neurons would be scored as labeled, whereas dimmer labeling would be scored as absent. Indeed, in some of the so-called subset Thyl lines, labeling of the few expressing cells is brighter than the brightest cells in any of the "full" lines. These labeling patterns are characteristic for a given Thyl-XFP line and are heritable, and numerous distinct lines that differ in labeling density, intensity, and expressed fluorophore are now available. With regard to subset labeling and the related nomenclature, it should be noted that the original Thy1-XFP lines were categorized as full or subset mostly based on the percentage of motor neurons labeled in a limited number of motor pools because the completeness of motor neuron labeling is easily scored by counterstaining synaptic sites in the periphery (Fig. 2). This nomenclature does not imply that a full line necessarily shows complete labeling of any other neuronal population, or even of all motor neurons in all motor pools. 
P. Marinković et al.
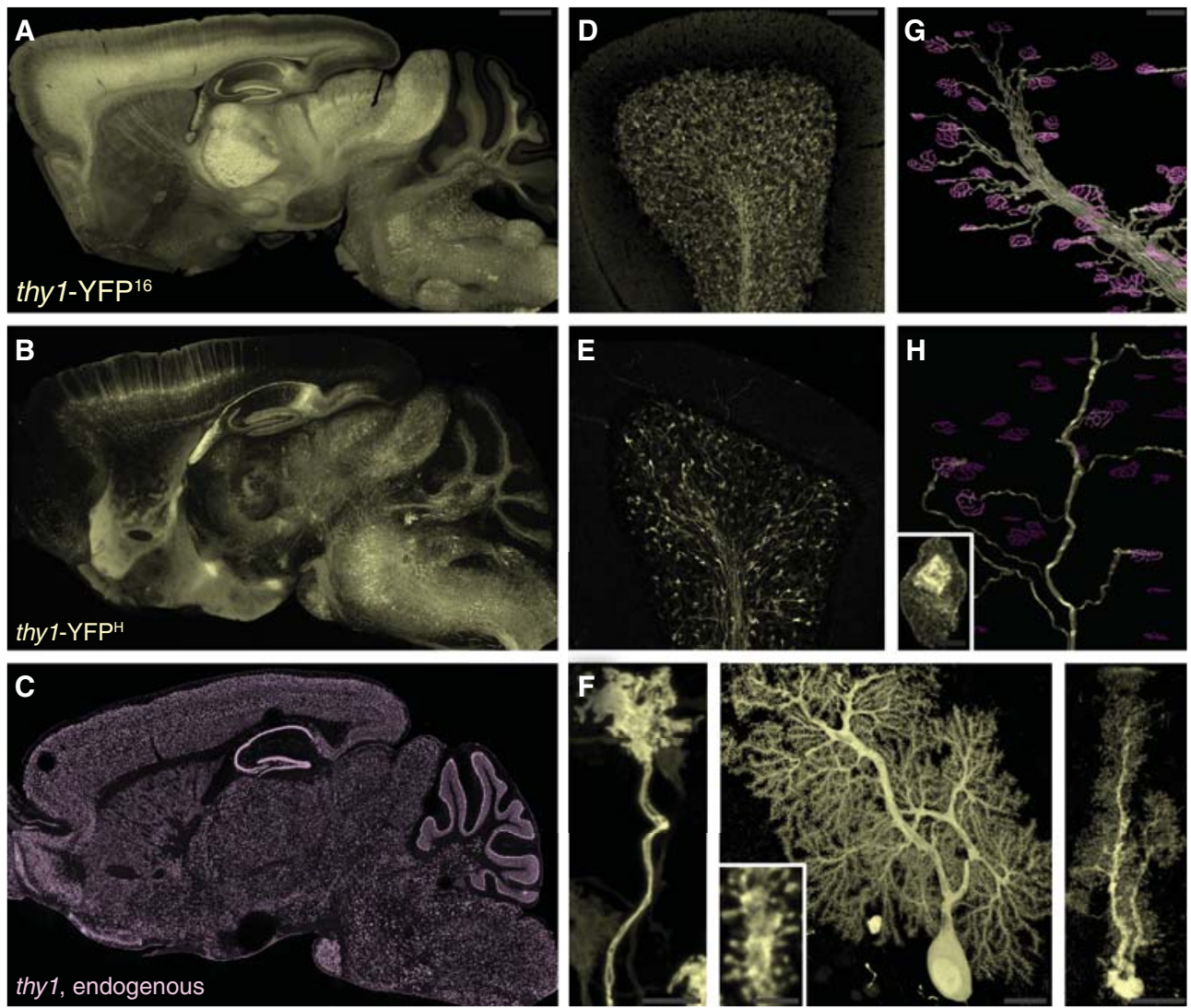

FIGURE 2. Two Thy 1 lines with typical sites of expression. $(A, D, G)$ Line Thy 1 -YFP ${ }^{16}$, a typical full line. $(B, E, F, H)$ Line Thy $1-\mathrm{YFP}^{\mathrm{H}}$, a subset line. $(C)$ In situ hybridization of endogenous expression pattern (modified from Allen Mouse Brain Atlas; contrast inverted). Confocal analysis of parasagittal sections $(A, B)$ shows that even a full line only labels subsets of most neuronal populations, albeit in this case, at a significantly higher frequency than in the subset line. $(D, E, F)$ Higher power views confirm this for the cerebellum. In-line Thy 1-YFP ${ }^{16}$ mossy fibers and parallel fibers are densely labeled, whereas line Thy $1-\mathrm{YFP}^{\mathrm{H}}$ shows sparse subset labeling in these axon populations (see isolated mossy fiber rosette in $F$, left). In addition, however, line Thy 1 -YFP ${ }^{\mathrm{H}}$ very occasionally also harbors labeled Purkinje cells $(F$, middle; inset shows spiny dendrites at full resolution) and even nonneuronal Bergmann glia $(F$, right). In the neuromuscular system, full lines, such as Thy1-YFP ${ }^{16}$, show complete overlap between preterminal axon labeling (yellow) and bungarotoxin-labeled postsynaptic sites (magenta label; $G$ ). In subset lines, such as line Thy1-YFP ${ }^{\mathrm{H}}$, motor units can be traced instead $(H$; inset shows a labeled nonneuronal cell). Lines were originally described in Feng et al. (2000). Scale bars: in $A, 1 \mathrm{~mm}$ (for $\mathrm{A}, \mathrm{B}$ ); in $D, 100 \mu \mathrm{m}$ (for $D, E$ ); in $F$ (left), $5 \mu \mathrm{m}$; in $F$ (center, right), $50 \mu \mathrm{m}$ (inset, 2.5 $\mathrm{mm}$ ); in $G, 50 \mu \mathrm{m}$ (for $G, H$ ). Images acquired on an FV1000 confocal system (Olympus) with 4X/0.13-NA air $(A, B)$, 20X/0.85-NA oil $(D, E)$, and 60X/1.42-NA oil (remaining panels) objectives. (C, Modified, with permission, from the Allen Mouse Brain Atlas 2010 [http://mouse.brain-map.org/viewlmage.do?imageld=68400987]; Lein et al. 2007.)

Still, a general tendency exists that lines with subset labeling in one population of neurons also show subset labeling of other neuronal populations. However, all Thy1 lines lack labeling of some neurons or neuronal subsets; hence, Thy1-driven expression should never uncritically be accepted as panneuronal. One unfortunate feature of Thy1-driven subset expression is its developmental dynamics. In many subset lines, the density of labeling increases as the animal ages, which can be an impediment in studies aimed at longitudinal reidentification of the same neurons. Moreover, at least based on anecdotal observations, the density of subset labeling in individual animals of a given line seems to be influenced by its genetic background (and even gender). As a consequence, different substrains of the original Thy1-XFP lines now likely exist, and in planning studies based on these animals, such variation should be taken into consideration.

The exact reasons for the subset expression found in Thyl-XFP lines remain unknown. Generally, this variability is ascribed to positional effects relating to insertion site and copy number of the transgene. Moreover, effects akin to position effect variegation could explain the subset character 

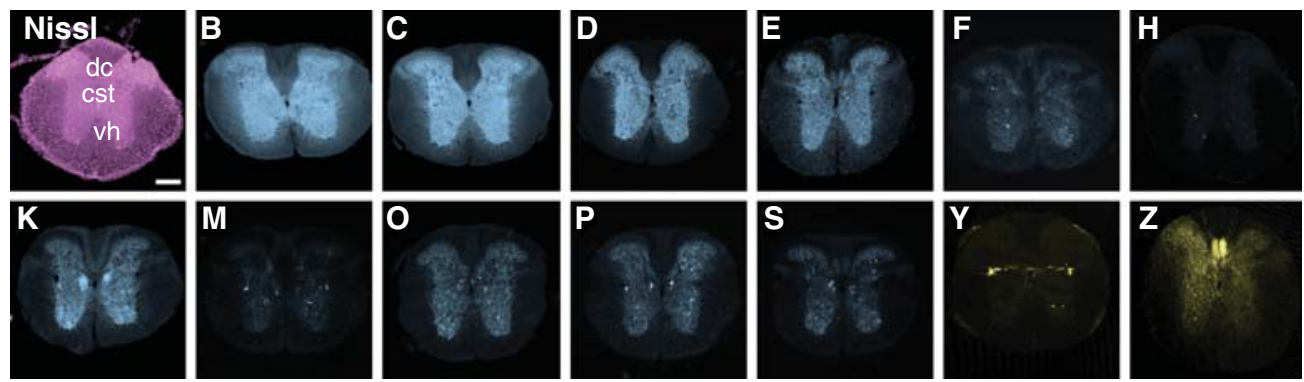

FIGURE 3. Spectrum of expression patterns found in a typical screen of founders. This figure shows the full spectrum of expression patterns found in the spinal cord of the MitoMice (Thy1-mitoCFP, cyan; Misgeld et al. 2007). Labeling density ranges from almost complete (e.g., lines $B, C$ ) to extremely sparse (line $H$ ). Subset labeling is not restricted to Thy 1-transgenic lines. Lines $Y$ and $Z$ were generated using neuron-specific enolase-derived regulatory elements to express mitoYFP (yellow). (Nse lines courtesy of R.W. Burgess, The Jackson Laboratory; images were taken in collaboration with M. Kerschensteiner, Ludwig-Maximilians University, Munich.) First image shows Nissl-like fluorescent stain (magenta) of a matched spinal cord section (cst, corticospinal tract; dc, dorsal column; vh, ventral horn). Scale bar, $250 \mu \mathrm{m}$. Images acquired on an FV1000 confocal system (Olympus) with a 4×/0.13 air objective.

of some lines (Feng et al. 2000). No study to date, however, has systematically explored this question or taken advantage of subset Thyl lines to define new neuronal cell classes based on the integration loci of the Thy1 transgenes.

\section{THY1 LINES}

\section{Overview of Available Thy1 Lines}

Since the description of the first Thy1-XFP lines by Feng et al. (2000), numerous additional sets of Thy1-driven transgenic lines that express a wide variety of conventional and functionalized fluorescent proteins have been reported. Initially, efforts aimed at widening the spectrum of available labeling patterns and colors (second generation). Additionally, attempts were initiated to systematically control subset labeling using the cre-loxP recombination system (third generation). In parallel, with the advent of well-characterized mammalian organelle targeting sequences and the proliferation of fluorescent-protein-based functional reporter constructs, numerous Thyl lines were generated that permit in vivo assaying of organelle distribution and transport, intraneuronal ion concentrations, neuronal spiking activity, and synaptic release. An overview of these lines, and the corresponding references, is provided in Table 1. Many of these lines are now available either through The Jackson Laboratory (http://www.jax.org) or directly from the laboratories that generated them. Considerable challenges for laboratories that generate Thy 1 lines are the financial and infrastructural requirements for line maintenance. Moreover, expression patterns in many of the reported lines have not been systematically documented, at least not in centralized public domain databases. Therefore, centralized deposition of frozen embryos or sperm, in addition to public domain documentation of expression patterns, should become a future priority.

\section{Generating Thy1 Lines}

The generation of new Thy 1 transgenic lines generally consists of five steps: (1) engineering and characterization of the desired fluorescent reporter protein, (2) cloning of the reporter protein into the Thyl vector, (3) linearization and purification of the new Thyl construct, (4) pronuclear injection to generate founders, and (5) screening of founder progeny to establish transgenic lines. Procedures for Steps 2 and 3 above are described in Generation of Thyl Constructs for Pronuclear Injection (Marinkovi et al. 2015a) and procedures for Step 5 are described in Generation of Tissue Sections for Screening Thy1 Mouse Lines (Marinkovi et al. 2015b) and Imaging Acute Neuromuscular Explants 
P. Marinković et al.

TABLE 1. Thy1 lines described in the literature

\begin{tabular}{|c|c|c|c|c|}
\hline Reference & Name & Purpose & Fluorophores & $\begin{array}{l}\text { Available at } \\
\text { The Jackson } \\
\text { Laboratory? }\end{array}$ \\
\hline \multicolumn{5}{|c|}{ First-generation Thy1-XFP lines } \\
\hline Feng et al. 2000 & Thy 1-XFP & Assessment of neuronal morphology & CFP, GFP, RFP, YFP & $\mathrm{Y}$ \\
\hline \multicolumn{5}{|c|}{ Second-generation Thy 1-XFP lines } \\
\hline De Paola et al. 2003 & Thy1-membXFP & Neuronal plasma membrane labeling & GFP & \\
\hline Hirrlinger et al. 2005 & Thy1-RCFP & Assessment of neuronal morphology & Coral FPs & \\
\hline \multicolumn{5}{|c|}{ Third-generation Thy1-XFP lines } \\
\hline Buffelli et al. 2003 & Thy1-STOP-YFP & Subset labeling and neuronal Cre reporter & YFP & $\mathrm{Y}$ \\
\hline Livet et al. 2007 & Brainbow & Multicolor labeling of neurons & CFP, GFP, RFP, YFP & $\mathrm{Y}$ \\
\hline \multicolumn{5}{|c|}{ Organellar Thy1-XFP lines } \\
\hline De Paola et al. 2003 & Thy1-synaptophysin-XFP & Synapse localization and SV trafficking & GFP, RFP & \\
\hline Umemori et al. 2004 & Thy1-synaptophysin-YFP & Synapse localization and SV trafficking & YFP & $\mathrm{Y}$ \\
\hline Südhof $2008^{\mathrm{a}}$ & Thy1-syntaxin1a-YFP & Synapse localization and SV trafficking & YFP & Y \\
\hline Han et al. 2005 & Thy1-synaptotagmin-YFP & Synapse localization and SV trafficking & CFP & Y \\
\hline Südhof $2008^{\mathrm{b}}$ & Thy1-VAMP2-CFP & Synapse localization and SV trafficking & CFP & Y \\
\hline Misgeld et al. 2007 & MitoMouse (Thy1-mitoCFP) & In vivo assessment of mitochondrial transport & CFP, YFP & Y \\
\hline \multicolumn{5}{|c|}{ Functionalized Thy1-XFP lines } \\
\hline Berglund et al. 2006 & Thy1-clomeleon & Ratiometric measurement of chloride levels & CFP/YFP & \\
\hline Heim et al. 2007 & Thy1-CerTN-L15 & FRET measurement of calcium levels & Cerulean/citrine & \\
\hline Arenkiel et al. 2007 & Thy1-ChR2-YFP & Optogenetic control of neuronal firing & YFP & $\mathrm{Y}$ \\
\hline Young et al. 2008 & SLICK & Cre-mediated recombination in labeled neurons & YFP & $\mathrm{Y}$ \\
\hline Li et al. 2005 & Thy 1-synapto-pHluorin & Synaptic transmitter release & YFP & \\
\hline Tabares et al. 2007 & Thy 1-synapto-pHluorin & Synaptic transmitter release & YFP & \\
\hline Wyatt et al. 2008 & Thy1-synapto-pHluorin & Synaptic transmitter release & YFP & \\
\hline
\end{tabular}

from Thy1 Mouse Lines (Marinkovi et al. 2015c). Step 1 (generation and characterization of desired reporter proteins) depends critically on the exact reporter being studied. Therefore, a general protocol cannot easily be provided. Often, fluorescent reporters are first characterized in simple cell lines, such as human embryonic kidney (HEK) cells. However, in our experience, a difficult problem remains that the performance in transgenic mice is often not easily predictable on this basis. For example, many fluorescent proteins that appear unproblematic in cell culture show aggregation when expressed at high levels in vivo. This represents a particular problem with fusion proteins, in which in vivo functionality can often not be proven. One approach is to cross the transgenic animal into a mutant strain that carries a deletion of the gene under study. Phenotypic rescue would suggest intact function of the fusion protein, provided expression is properly targeted. Such a stringent assay, however, is rarely possible and requires considerable breeding efforts. Methods that allow transient overexpression in mice (such as in utero electroporation) can provide valuable hints with regard to in vivo performance of a new reporter. Given these challenges, plus the cost and effort involved in making transgenic animals, it often is advisable to err on the side of caution and use transgenic fluorescent proteins that have been tested in vivo already, rather than use the product of the latest improvement in fluorescent protein engineering.

After the desired fluorescent protein reporter sequence is cloned into the Thy1 vector (see Generation of Thyl Constructs for Pronuclear Injection [Marinković et al. 2015a]), it must be sent to a facility specializing in pronuclear injection (Step 4). After successful pronuclear injection, the transgenic facility will generally transfer a set of polymerase chain reaction (PCR)-confirmed founders (i.e., animals that, on tail biopsy, were found to contain the Thy 1 vector sequences). To screen for functional expression, we cross founders with commercially obtained inbred mice (typically C57BL/6). 
Animals of the $\mathrm{F}_{1}$ generation are screened at $3 \mathrm{wk}$ of age, when Thy1-driven expression has typically reached high levels. In most cases, more than half of the PCR-confirmed founders have proteinexpressing offspring. So as not to jeopardize lines during screening, it is important to always keep sufficient numbers of PCR-confirmed breeders until the screening process for a given line is complete.

For screening, we typically prepare acute nerve-muscle explants (see Imaging Acute Neuromuscular Explants from Thy1 Mouse Lines [Marinkovi et al. 2015c]) in parallel to transcardial perfusion (see Generation of Tissue Sections for Screening Thy1 Mouse Lines [Marinković et al. 2015b]) because fixation can weaken fluorescence and create misleading autofluorescence. In addition, this allows the first functional tests of the expressed biosensors. Positive lines are then established by further crossing into the in-bred strain, and the lines are maintained by PCR-based selection of positive animals. Once the desired level of backcrossing to a defined genetic background is reached, animals can be homozygozed for the transgene by brother-sister inbreeding.

Because screening, for cost and space reasons, is typically performed in the $F_{1}$ generation, changes in expression patterns are possible in future generations because of multiple insertions of the transgene that segregate. Similarly, changes in genetic background can affect expression patterns. Therefore, new lines should be regularly checked for stability of the desired expression patterns, and care should be taken to indicate generation numbers when first describing new lines.

Fluorescent proteins can modulate protein function or even exert toxic effects when fused to functional domains (Han et al. 2005) or when expressed at very high levels (Bridge et al. 2009). Therefore, careful functional studies of fusion proteins before and after transgenic mouse generation are necessary. Generally, it is advisable to maintain lines that show lower levels of fluorescent reporter protein in addition to highly expressing lines.

\section{ACKNOWLEDGMENTS}

We thank Martin Kerschensteiner, Ludwig-Maximilians University Munich, Rob Burgess, Jackson Laboratory, and Jeff Lichtman, Harvard University, for collaboration on obtaining the pictures shown in Figure 3. We also acknowledge the kind permission of the Allen Brain Institute to use Figure 2C. Work in our laboratory is supported by the Alexander-von-Humboldt foundation, the TUM Institute for Advanced Study, and the Bundesministerium für Bildung und Forschung (BMBF).

\section{REFERENCES}

Aigner L, Arber S, Kapfhammer JP, Laux T, Schneider C, Botteri F, Brenner HR, Caroni P. 1995. Overexpression of the neural growth-associated protein GAP-43 induces nerve sprouting in the adult nervous system of transgenic mice. Cell 83: 269-278.

Andra K, Abramowski D, Duke M, Probst A, Wiederhold KH, Burki K, Goedert M, Sommer B, Staufenbiel M. 1996. Expression of APP in transgenic mice: A comparison of neuron-specific promoters. Neurobiol Aging 17: 183-190.

Arenkiel BR, Peca J, Davison IG, Feliciano C, Deisseroth K, Augustine GJ, Ehlers MD, Feng G. 2007. In vivo light-induced activation of neural circuitry in transgenic mice expressing channelrhodopsin-2. Neuron 54 : 205-218.

Berglund K, Schleich W, Krieger P, Loo LS, Wang D, Cant NB, Feng G, Augustine GJ, Kuner T. 2006. Imaging synaptic inhibition in transgenic mice expressing the chloride indicator, Clomeleon. Brain Cell Biol 35: 207-228.

Bridge KE, Berg N, Adalbert R, Babetto E, Dias T, Spillantini MG, Ribchester RR, Coleman MP. 2009. Late onset distal axonal swelling in YFP-H transgenic mice. Neurobiol Aging 30: 309-321.

Buffelli M, Burgess RW, Feng G, Lobe CG, Lichtman JW, Sanes JR. 2003. Genetic evidence that relative synaptic efficacy biases the outcome of synaptic competition. Nature 424: 430-434.

Caroni P. 1997. Overexpression of growth-associated proteins in the neurons of adult transgenic mice. J Neurosci Methods 71: 3-9.
De Paola V, Arber S, Caroni P. 2003. AMPA receptors regulate dynamic equilibrium of presynaptic terminals in mature hippocampal networks. Nat Neurosci 6: 491-500.

Feng G, Mellor RH, Bernstein M, Keller-Peck C, Nguyen QT, Wallace M, Nerbonne JM, Lichtman JW, Sanes JR. 2000. Imaging neuronal subsets in transgenic mice expressing multiple spectral variants of GFP. Neuron 28: $41-51$

Gan WB, Kwon E, Feng G, Sanes JR, Lichtman JW. 2003. Synaptic dynamism measured over minutes to months: Age-dependent decline in an autonomic ganglion. Nat Neurosci 6: 956-960.

Grutzendler J, Kasthuri N, Gan WB. 2002. Long-term dendritic spine stability in the adult cortex. Nature 420: 812-816.

Han W, Rhee JS, Maximov A, Lin W, Hammer RE, Rosenmund C, Sudhof TC. 2005. C-terminal ECFP fusion impairs synaptotagmin 1 function: Crowding out synaptotagmin 1. J Biol Chem 280: 50895100 .

Heim N, Garaschuk O, Friedrich MW, Mank M, Milos RI, Kovalchuk Y, Konnerth A, Griesbeck O. 2007. Improved calcium imaging in transgenic mice expressing a troponin C-based biosensor. Nat Methods 4: $127-129$.

Hirrlinger PG, Scheller A, Braun C, Quintela-Schneider M, Fuss B, Hirrlinger J, Kirchhoff F. 2005. Expression of reef coral fluorescent proteins in the central nervous system of transgenic mice. Mol Cell Neurosci 30: 291-303. 


\section{P. Marinković et al.}

Holtmaat A, Svoboda K. 2009. Experience-dependent structural synaptic plasticity in the mammalian brain. Nat Rev Neurosci 10: 647-658.

Ingraham HA, Lawless GM, Evans GA. 1986. The mouse Thy-1.2 glycoprotein gene: Complete sequence and identification of an unusual promoter. J Immunol 136: 1482-1489.

Lein ES, Hawrylycz MJ, Ao N, Ayres M, Bensinger A, Bernard A, Boe AF, Boguski MS, Brockway KS, Byrnes EJ, et al. 2007. Genome-wide atlas of gene expression in the adult mouse brain. Nature 445: $168-176$.

Li Z, Burrone J, Tyler WJ, Hartman KN, Albeanu DF, Murthy VN. 2005. Synaptic vesicle recycling studied in transgenic mice expressing synaptopHluorin. Proc Natl Acad Sci 102: 6131-6136.

Lichtman JW, Sanes JR. 2003. Watching the neuromuscular junction. Neurocytol 32: 767-775.

Livet J, Weissman TA, Kang H, Draft RW, Lu J, Bennis RA, Sanes JR, Lichtman JW. 2007. Transgenic strategies for combinatorial expression of fluorescent proteins in the nervous system. Nature 450: 56-62.

Marinkovi P, Godinho L, Misgeld T. 2015a. Generation of Thy1 constructs for pronuclear injection. Cold Spring Harb Protoc doi: 10.1101/pdb. prot087676.

Marinkovi P, Godinho L, Misgeld T. 2015b. Generation of tissue sections for screening Thy1 mouse lines. Cold Spring Harb Protoc doi: 10.1101/ pdb.prot087684.

Marinkovi P, Godinho L, Misgeld T. 2015c. Imaging acute neuromuscular explants from Thy1 mouse lines. Cold Spring Harb Protoc doi: 10.1101/ pdb.prot087692.

Misgeld T, Kerschensteiner M. 2006. In vivo imaging of the diseases nervous system. Nat Rev Neurosci 7: 449-463.

Misgeld T, Kerschensteiner M, Bareyre FM, Burgess RW, Lichtman JW. 2007. Imaging axonal transport of mitochondria in vivo. Nat Methods 4: 559-561.

Morris R. 1985. Thy-1 in developing nervous tissue. Dev Neurosci 7: 133160.

is Morris R. 1992. Thy-1, the enigmatic extrovert on the neuronal surface. Bioessays 14: 715-722.
Pan F, Gan WB. 2008. Two-photon imaging of dendritic spine development in the mouse cortex. Dev Neurobiol 68: 771-778.

Ramon y Cajal S. 1904. Texture of the nervous system of man and the vertebrates. Springer, New York.

Tabares L, Ruiz R, Linares-Clemente P, Gaffield MA, Alvarez de Toledo G, Fernandez-Chacon R, Betz WJ. 2007. Monitoring synaptic function at the neuromuscular junction of a mouse expressing synaptopHluorin. $J$ Neurosci 27: 5422-5430.

Trachtenberg JT, Chen BE, Knott GW, Feng G, Sanes JR, Welker E, Svoboda K. 2002. Long-term in vivo imaging of experience-dependent synaptic plasticity in adult cortex. Nature 420: 788-794.

Umemori H, Linhoff MW, Ornitz DM, Sanes JR. 2004. FGF22 and its close relatives are presynaptic organizing molecules in the mammalian brain. Cell 118: 257-270

Vidal M, Morris R, Grosveld F, Spanopoulou E. 1990. Tissue-specific control elements of the Thy-1 gene. EMBO J 9: 833-840.

Walsh MK, Lichtman JW. 2003. In vivo time-lapse imaging of synaptic takeover associated with naturally occurring synapse elimination. Neuron 37: 67-73.

Wilt BA, Burns LD, Wei Ho ET, Ghosh KK, Mukamel EA, Schnitzer MJ. 2009. Advances in light microscopy for neuroscience. Annu Rev Neurosci 32: 435-506.

Wyatt RM, Balice-Gordon RJ. 2008. Heterogeneity in synaptic vesicle release at neuromuscular synapses of mice expressing synaptopHluorin. J Neurosci 28: 325-335.

Xu T, Yu X, Perlik AJ, Tobin WF, Zweig JA, Tennant K, Jones T, Zuo Y. 2009. Rapid formation and selective stabilization of synapses for enduring motor memories. Nature 462: 915-919.

Yang G, Pan F, Gan WB. 2009. Stably maintained dendritic spines are associated with lifelong memories. Nature 462: 920-924.

Young P, Feng G. 2004. Labeling neurons in vivo for morphological and functional studies. Curr Opin Neurobiol 14: 642-646.

Young P, Qiu L, Wang D, Zhao S, Gross J, Feng G. 2008. Single-neuron labelling with inducible Cre-mediated knockout in transgenic mice. Nat Neurosci 11: 721-728. 


\section{Generation and Screening of Transgenic Mice with Neuronal Labeling Controlled by Thy1 Regulatory Elements}

Petar Marinkovic, Leanne Godinho and Thomas Misgeld

Cold Spring Harb Protoc; doi: 10.1101/pdb.top087668

\begin{tabular}{rc}
$\begin{array}{r}\text { Email Alerting } \\
\text { Service }\end{array}$ & Receive free email alerts when new articles cite this article - click here. \\
\hline $\begin{array}{r}\text { Subject } \\
\text { Categories }\end{array}$ & $\begin{array}{c}\text { Browse articles on similar topics from Cold Spring Harbor Protocols. } \\
\text { Imaging for Neuroscience (342 articles) } \\
\text { Transgenic Mice (139 articles) } \\
\text { Transgenic Technology, general (187 articles) }\end{array}$ \\
\hline
\end{tabular}

